\title{
molecules
}

ISSN 1420-3049

www.mdpi.com/journal/molecules

Article

\section{Benchmark Study on the Smallest Bimolecular Nucleophilic Substitution Reaction: $\mathrm{H}^{-}+\mathrm{CH}_{4} \rightarrow \mathrm{CH}_{4}+\mathrm{H}^{-}$}

\section{Marcel Swart ${ }^{1,2 *}$ and F. Matthias Bickelhaupt ${ }^{3,4}$}

1 Institució Catalana de Recerca i Estudis Avançats (ICREA), Pg. Lluís Companys 23, 08010 Barcelona, Spain

2 Institut de Química Computacional i Catàlisi (IQCC) and Departament de Química, Universitat de Girona, Campus Montilivi, 17071 Girona, Spain

3 Department of Theoretical Chemistry \& Amsterdam Center for Multiscale Modeling, VU University, De Boelelaan 1083, 1081 HV Amsterdam, The Netherlands;

E-Mail: f.m.bickelhaupt@vu.nl

4 Institute of Molecules and Materials, Radboud University Nijmegen, Heyendaalseweg 135, 6525 AJ Nijmegen, The Netherlands

* Author to whom correspondence should be addressed; E-Mail: marcel.swart@icrea.cat; Tel.: +34-972-418-861; Fax: +34-972-418-356.

Received: 20 May 2013; in revised form: 3 June 2013 / Accepted: 28 June 2013 /

Published: 3 July 2013

\begin{abstract}
We report here a benchmark study on the bimolecular nucleophilic substitution $\left(\mathrm{S}_{\mathrm{N}} 2\right)$ reaction between hydride and methane, for which we have obtained reference energies at the coupled cluster toward full configuration-interaction limit (CC-cf/CBS). Several wavefunction (HF, MP2, coupled cluster) and density functional methods are compared for their reliability regarding these reference data.
\end{abstract}

Keywords: $\mathrm{S}_{\mathrm{N}} 2$ reaction; density functional theory; benchmark study; coupled cluster theory; bimolecular substitution; gas phase reactivity

\section{Introduction}

Bimolecular substitution $\left(\mathrm{S}_{\mathrm{N}} 2\right)$ reactions play an important role in organic chemistry and in biochemistry (DNA replication mechanism). Interestingly, there is a profound solvent effect present which has a major effect on the reaction barriers and intermediates. For example, the prototypical $\mathrm{S}_{\mathrm{N}} 2$ 
reaction of chloride with methyl chloride shows in the gas phase a double-well potential (see Figure 1) with deep wells and a reduced barrier. On the other hand, in solution the energy profile turns basically into a unimodal reaction [1-12] (see Figure 1), accompanied by a significant increase of the reaction barrier. In previous studies [13-42] it was shown that coupled cluster methods in general give accurate results for the energy profile of $\mathrm{S}_{\mathrm{N}} 2$ reactions, while density functional methods give qualitatively correct results but often underestimate barriers [15]. This has led to the design of new and improved density functionals (SSB-D [43], S12g [44] and S12h [44]), where in particular the latter hybrid functional $(\mathrm{S} 12 \mathrm{~h})$ was shown to provide accurate results for the complete energy profile of $\mathrm{S}_{\mathrm{N}} 2$ reactions.

Figure 1. Energy profile for $\mathrm{S}_{\mathrm{N}} 2$ reaction in gas phase and in solution.

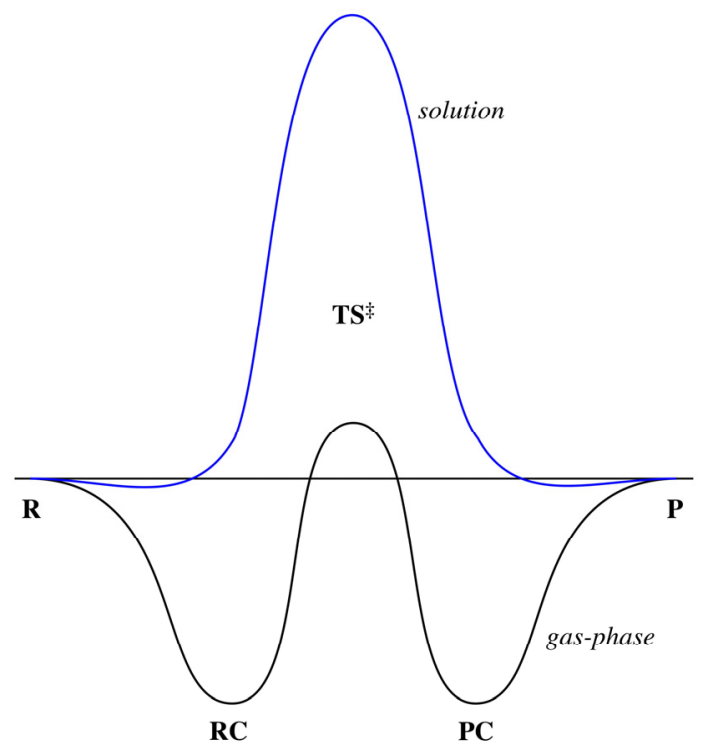

Here we have studied the smallest $\mathrm{S}_{\mathrm{N}} 2$ reaction possible, between hydride and methane:

$$
\mathrm{H}^{-}+\mathrm{CH}_{3} \mathrm{H} \Longrightarrow \begin{array}{ccc}
\delta- & \delta- \\
\mathrm{H}^{-\cdots} \mathrm{CH}_{3} \cdots \mathrm{H}^{\cdots}
\end{array} \Longrightarrow \mathrm{CH}_{3} \mathrm{H}+\mathrm{H}^{-}
$$

For this reaction, we have been able to perform coupled cluster calculations [45] up to the level of CCSDT/aug-cc-pVTZ, and through extrapolation techniques we have obtained reference data at $\mathrm{CC}$-cf/CBS (CC-cf=continued fraction [46] extrapolation toward full-CI limit; CBS = Complete Basis Set). Moreover, we have explored the energy profile for this reaction with 28 density functionals, (LDA, [47-49] PBE, [50] PBE-D 3 , [50,51] PBE0, [52-54] PBE0-D 2, [51-54] PW91, [55,56] BP86, [57,58] revPBE, [59] OPBE, [50,60,61] OLYP, [61,62] B3LYP, [63,64] B3LYP-D 3 , [51,63,64] BLYP, [57,62] B2PLYP, [65] M06, [66] M06-2X, [66] M06-L, [67] B97, [68] B97-3, [69] B97-D 2, [51] TPSS, [70] TPSS-D $_{3}$, [51,70] TPSSh, [71] SSB-D, [43] S12g, [44] S12h, [44] CAM-S12h, [44] CAM-B3LYP [72]), among which the most popular ones from the DFT2012 popularity poll [73] and the newly developed S12g/S12h functional [44]. 


\section{Results and Discussion}

The complete energy profile for the $\mathrm{S}_{\mathrm{N}} 2$ reaction of $\mathrm{H}^{-}+\mathrm{CH}_{4}$ was studied using both wavefunction and density functional methods. The reaction proceeds from the reactants ( $R$, see Figure 1) towards a reactant complex (RC) and then crosses the central barrier (TS) to reach a product complex (PC) and finally products (P). The RC is reached early on, e.g., with a C-H(nucleophile) distance of some $3.84 \AA$; this is ca. $0.7 \AA$ longer than the case of $\mathrm{Cl}^{-}+\mathrm{CH}_{3} \mathrm{Cl}(3.15 \AA)$ even though the size of the nucleophile is probably much smaller here [note however that Pauling [74] reported a larger ionic radius for $H^{-}$ $(2.08 \AA)$ than for $\mathrm{Cl}^{-}$(1.81 A), while Frecer [75,76] through Monte Carlo obtained values of $2.28 \AA$ $\left(\mathrm{H}^{-}\right)$and $2.30 \mathrm{~A}\left(\mathrm{Cl}^{-}\right)$respectively]. This is consistent with a very weak ion-molecule interaction in the reactant complexes. Interestingly enough, at the highest level for which we could obtain the energies directly, CCSDT/atz (see Table 1), this leads to an energy profile of this gas-phase reaction that is more reminiscent of an $\mathrm{S}_{\mathrm{N}} 2$ profile in solution [1,2,77] (see Figure 1). For example, the RC well is almost non-existent with a depth of $0.9 \mathrm{kcal} \cdot \mathrm{mol}^{-1}$ and the barrier is quite steep with a value of $49.4 \mathrm{kcal} \cdot \mathrm{mol}^{-1}$.

\subsection{Coupled Cluster Results}

We extrapolated the coupled cluster energies to come as close as possible to the full-CI result, for which we use the continued-fraction approximant [46]. There are two possibilities for this extrapolation (Equations 1a,b), using either the $\operatorname{CCSD}(\mathrm{T})$ energy (as we do here in this first part), or the CCSDT energy (as discussed later on), for the $\delta_{3}$ ingredient. The resulting $E_{C C \text {-cf }}$ energies are also given in Table 1:

$$
\begin{aligned}
& E_{C C-c f}=\frac{\delta_{1}}{1-\frac{\delta_{2} / \delta_{1}}{1-\delta_{3 a} / \delta_{2}}} ; \delta_{1}=E_{R H F} ; \delta_{2}=E_{C C S D}-E_{R H F} ; \delta_{3 a}=E_{C C S D(T)}-E_{C C S D} \\
& E_{C C-c f}=\frac{\delta_{1}}{1-\frac{\delta_{2} / \delta_{1}}{1-\delta_{3 b} / \delta_{2}}} ; \delta_{1}=E_{R H F} ; \delta_{2}=E_{C C S D}-E_{R H F} ; \delta_{3 b}=E_{C C S D T}-E_{C C S D}
\end{aligned}
$$

The results of Table 1 make it clear that there is a clear basis set effect, where it is not really important to increase the basis set size but it is more important to include diffuse functions [42,78]. Given that we deal here with anionic species, for which diffuse functions are important $[21,42,79]$, this comes as no surprise. There is also a significant electron-correlation effect, where energies obtained at the CCSDT level do not seem to have converged to the full-CI limit. For instance, the well depth increases with the atz basis from $-0.27 \mathrm{kcal} \cdot \mathrm{mol}^{-1}$ (RHF) to $-0.69 \mathrm{kcal} \cdot \mathrm{mol}^{-1}$ at CCSD, $-0.90 \mathrm{kcal} \cdot \mathrm{mol}^{-1}$ at $\operatorname{CCSD}(\mathrm{T}),-0.93 \mathrm{kcal} \cdot \mathrm{mol}^{-1}$ at CCSDT and $-1.22 \mathrm{kcal} \cdot \mathrm{mol}^{-1}$ at CC-cf. Likewise, the barrier continues to drop from $62.6 \mathrm{kcal} \cdot \mathrm{mol}^{-1}$ at RHF to $49.4 \mathrm{kcal} \cdot \mathrm{mol}^{-1}$ at CCSDT, and reaches $49.0 \mathrm{kcal} \cdot \mathrm{mol}^{-1}$ at CC-cf. It should be noted that the perturbative triples approach in $\mathrm{CCSD}(\mathrm{T})$ gives a good approximation for the CCSDT energies (difference $0.05-0.30 \mathrm{kcal} \cdot \mathrm{mol}^{-1}$ ). Based on the extrapolation towards full-CI and complete basis set with CC-cf at increasingly larger basis sets (CC-cf/CBS), final reference energies of $-1.20 \mathrm{kcal} \cdot \mathrm{mol}^{-1}$ (RC) and $+48.90 \mathrm{kcal} \cdot \mathrm{mol}^{-1}$ (TS) are obtained. 
Table 1. Relative energies $\left(\mathrm{kcal} \cdot \mathrm{mol}^{-1}\right)$ obtained with wavefunction and density functional methods ${ }^{\text {a }}$.

\begin{tabular}{|c|c|c|c|c|c|c|c|c|c|c|c|c|}
\hline & dz & tz & $\mathbf{q z}$ & $\mathbf{a d z}$ & atz & aqz & dz & tz & $\mathbf{q z}$ & adz & atz & $\mathbf{a q z}$ \\
\hline & $\mathrm{RC}$ & $\mathrm{RC}$ & $\mathrm{RC}$ & $\mathrm{RC}$ & $\mathrm{RC}$ & $\mathrm{RC}$ & TS & TS & TS & TS & TS & TS \\
\hline RHF & -2.55 & -2.02 & -1.70 & -0.27 & -0.27 & -0.27 & 52.90 & 56.86 & 58.47 & 61.98 & 62.59 & 62.61 \\
\hline MP2 & -3.41 & -3.15 & -2.93 & -0.87 & -0.91 & -0.87 & 43.89 & 46.44 & 47.28 & 49.36 & 50.19 & 50.21 \\
\hline CCSD & -3.53 & -3.26 & -2.99 & -0.70 & -0.69 & -0.62 & 42.23 & 45.95 & 47.61 & 51.87 & 52.97 & 53.03 \\
\hline $\operatorname{CCSD}(\mathrm{T})$ & -3.66 & -3.46 & -3.23 & -0.88 & -0.90 & -0.85 & 40.20 & 43.41 & 44.73 & 48.88 & 49.67 & 49.63 \\
\hline CCSDT & -3.68 & -3.49 & $\mathrm{n} / \mathrm{a}^{\mathrm{b}}$ & -0.92 & -0.93 & $\mathrm{n} / \mathrm{a}^{\mathrm{b}}$ & 39.92 & 43.10 & 44.41 & 48.61 & 49.42 & $\mathrm{n} / \mathrm{a}^{\mathrm{b}}$ \\
\hline $\mathrm{CC}-\mathrm{cf}^{\mathrm{c}}$ & -3.80 & -3.71 & -3.53 & -1.13 & -1.22 & -1.19 & 39.83 & 42.85 & 44.07 & 48.30 & 48.95 & 48.87 \\
\hline LDA & -10.07 & -7.78 & -6.86 & -3.08 & -2.77 & -2.74 & 22.86 & 28.01 & 29.83 & 33.26 & 34.12 & 34.16 \\
\hline PBE & -7.72 & -5.69 & -5.14 & -1.99 & -1.85 & -1.83 & 27.68 & 32.76 & 34.49 & 38.26 & 39.00 & 39.09 \\
\hline $\mathrm{PBE}-\mathrm{D}_{3}$ & -8.01 & -5.98 & -5.40 & -2.21 & -2.05 & -2.03 & 27.43 & 32.51 & 34.25 & 38.05 & 38.80 & 38.88 \\
\hline PBE0 & -5.56 & -4.18 & -3.69 & -1.18 & -1.08 & -1.07 & 35.04 & 39.61 & 41.21 & 44.38 & 45.03 & 45.08 \\
\hline $\mathrm{PBE} 0-\mathrm{D}_{3}$ & -5.84 & -4.43 & -3.92 & -1.36 & -1.25 & -1.24 & 34.77 & 39.35 & 40.96 & 44.16 & 44.81 & 44.86 \\
\hline PW91 & -7.97 & 5.95 & -5.49 & -2.46 & -2.37 & -2.37 & 27.32 & 32.46 & 34.12 & 37.76 & 38.52 & 38.59 \\
\hline BP86 & -6.50 & -4.39 & -3.74 & -0.78 & -0.65 & -0.62 & 28.34 & 33.58 & 35.49 & 39.31 & 40.24 & 40.32 \\
\hline revPBE & -6.48 & -4.64 & -4.23 & -1.54 & -1.50 & -1.51 & 30.16 & 35.20 & 36.87 & 40.62 & 41.29 & 41.38 \\
\hline OPBE & -4.72 & -3.53 & -3.34 & $\mathrm{n} / \mathrm{a}^{\mathrm{d}}$ & $\mathrm{n} / \mathrm{a}^{\mathrm{d}}$ & $\mathrm{n} / \mathrm{a}^{\mathrm{d}}$ & 34.49 & 38.87 & 40.18 & 43.01 & 43.22 & 43.28 \\
\hline OLYP & -6.28 & -4.77 & -4.57 & $\mathrm{n} / \mathrm{a}^{\mathrm{d}}$ & $\mathrm{n} / \mathrm{a}^{\mathrm{d}}$ & $\mathrm{n} / \mathrm{a}^{\mathrm{d}}$ & 33.46 & 38.29 & 39.71 & 43.28 & 43.82 & 43.92 \\
\hline B3LYP & -5.73 & -4.02 & -3.50 & -0.78 & -0.73 & -0.72 & 34.40 & 39.49 & 41.20 & 44.78 & 45.84 & 45.91 \\
\hline B3LYP-D 3 & -6.12 & -4.35 & -3.80 & -0.98 & -0.91 & -0.89 & 33.91 & 39.03 & 40.75 & 44.39 & 45.46 & 45.53 \\
\hline BLYP & -7.34 & -5.02 & -4.44 & -1.22 & -1.18 & -1.18 & 28.63 & 34.32 & 36.17 & 40.35 & 41.56 & 41.66 \\
\hline B2PLYP & -4.21 & -3.00 & -2.51 & +0.02 & +0.03 & +0.04 & 38.49 & 42.52 & 43.97 & 47.40 & 48.46 & 48.53 \\
\hline M06 & -5.54 & -3.99 & -3.92 & -1.80 & -1.84 & -2.01 & 36.87 & 41.94 & 42.50 & 46.29 & 46.56 & 46.13 \\
\hline M06-2X & -5.61 & -4.43 & -2.42 & -1.26 & -1.10 & -1.06 & 36.08 & 41.35 & 43.58 & 45.16 & 47.11 & 46.95 \\
\hline M06-L & -5.46 & -4.27 & -3.76 & -1.27 & -1.19 & -1.18 & 39.80 & 44.00 & 45.67 & 48.79 & 49.35 & 49.45 \\
\hline B97 & -5.72 & -4.30 & -3.84 & -1.24 & -1.15 & -1.11 & 34.31 & 38.99 & 40.70 & 44.14 & 44.96 & 45.11 \\
\hline B97-3 & -4.78 & -3.55 & -3.00 & -0.63 & -0.51 & -0.44 & 37.68 & 41.99 & 43.82 & 47.32 & 48.26 & 48.46 \\
\hline B97- $\mathrm{D}_{2}$ & -6.57 & -4.62 & -4.14 & -1.33 & -1.21 & -1.20 & 28.69 & 33.93 & 35.74 & 40.05 & 41.03 & 41.08 \\
\hline TPSS & -5.58 & -4.10 & -3.69 & -1.38 & -1.33 & -1.32 & 30.75 & 35.82 & 37.35 & 40.33 & 41.27 & 41.30 \\
\hline TPSS- $\mathrm{D}_{3}$ & -5.98 & -4.44 & -4.00 & -1.60 & -1.51 & -1.50 & 30.37 & 35.47 & 37.00 & 40.01 & 40.97 & 40.99 \\
\hline TPSSh & -5.05 & -3.73 & -3.33 & -1.12 & -1.07 & -1.06 & 33.34 & 38.25 & 39.76 & 42.61 & 43.51 & 43.52 \\
\hline SSB-D & -7.89 & -6.12 & -5.54 & -2.15 & -2.04 & -2.01 & 30.65 & 35.04 & 36.82 & 40.55 & 41.08 & 41.20 \\
\hline $\mathrm{S} 12 \mathrm{~g}$ & -8.20 & -6.36 & -5.77 & -2.33 & -2.18 & -2.15 & 30.36 & 34.95 & 36.74 & 40.51 & 41.10 & 41.21 \\
\hline $\mathrm{S} 12 \mathrm{~h}$ & -6.18 & -4.74 & -4.18 & -1.47 & -1.37 & -1.35 & 36.51 & 40.99 & 42.66 & 45.97 & 46.60 & 46.67 \\
\hline CAM-S12h & -5.71 & -4.38 & -3.83 & -1.31 & -1.22 & -1.21 & 38.35 & 42.83 & 44.50 & 47.72 & 48.35 & 48.41 \\
\hline CAM-B3LYP & -5.03 & -3.62 & -3.09 & -0.64 & -0.61 & -0.60 & 38.85 & 43.88 & 45.61 & 49.11 & 50.03 & 50.08 \\
\hline
\end{tabular}

${ }^{a}$ energies relative to reactants, for each method at their own optimized geometry; ${ }^{b}$ not available due to insufficient computational resources; ${ }^{\mathrm{c}}$ obtained with equation 1a at $\operatorname{CCSD}(\mathrm{T})$ optimized geometry; ${ }^{\mathrm{d}}$ not available due to dissociation towards reactants, i.e., no $\mathrm{RC}-$ complex found.

The results obtained with the different levels of coupled cluster method, i.e., CCSD, CCSD(T), CCSDT and CC-cf, together with RHF and MP2 (see Table 1) indicate that CCSD may be sufficient for getting good results. CCSD underestimates the RC well depth (e.g., by $0.3-0.6 \mathrm{kcal} \cdot \mathrm{mol}^{-1}$ ), and overestimates the barrier by ca. 3-4 $\mathrm{kcal} \cdot \mathrm{mol}^{-1}$. MP2 works in this respect even better with deviations from CC-cf that are twice as small, even though the computational effort is more or less the same as 
CCSD. As already noted often before, RHF cannot be trusted for these energy profiles as it gives barriers which are too large.

\subsection{Density Functional Energies}

All density functionals show the correct energy profile with a shallow well for the RC ( -0.4 to $-2.7 \mathrm{kcal} \cdot \mathrm{mol}^{-1}$ with the largest basis set aqz), and a substantial barrier ( 34.2 to $50.1 \mathrm{kcal} \cdot \mathrm{mol}^{-1}$ with the aqz basis). Nevertheless, the results for the 28 density functionals show quite a diversity in the accuracy for the energy profile, even though some general trends are obvious: they tend to overestimate the $\mathrm{RC}$ well depth, and (generally) underestimate the reaction barrier. The least reliable functional is not surprisingly LDA, which for the RC predicts a well depth of $-2.74 \mathrm{kcal} \cdot \mathrm{mol}^{-1}$, and places the TS at $+34.16 \mathrm{kcal} \cdot \mathrm{mol}^{-1}$ (e.g., a deviation of ca. $15 \mathrm{kcal} \cdot \mathrm{mol}^{-1}$ ). Early GGA functionals (PBE, BP86 [80], BLYP) improve the barrier by ca. $5-7 \mathrm{kcal}^{\circ} \mathrm{mol}^{-1}$, and a further $3 \mathrm{kcal} \cdot \mathrm{mol}^{-1}$ is obtained by the use of OPTX in OPBE/OLYP. Surprisingly, SSB-D predicts a barrier that is ca. $2.0 \mathrm{kcal} \cdot \mathrm{mol}^{-1}$ lower than OPBE, even though prior studies showed them to behave similarly. This cannot be due to the inclusion of dispersion in SSB-D, since the effect of including Grimme's dispersion energy is limited $\left(<0.5 \mathrm{kcal} \cdot \mathrm{mol}^{-1}\right.$, see Table 1$)$. Even better results are obtained with hybrid functionals and reasonable results are obtained: the difference with the $\mathrm{CC}$-cf results is now only $3-4 \mathrm{kcal} \cdot \mathrm{mol}^{-1}$ (at a fraction of the computational cost) for the most often used hybrid functionals (B3LYP, PBE0, M06). The recently developed S12h and M06-2X bring the deviation from CC-cf down to ca. $2 \mathrm{kcal} \cdot \mathrm{mol}^{-1}$, while excellent results (deviation $<0.5 \mathrm{kcal} \cdot \mathrm{mol}^{-1}$ ) are obtained with four functionals: B2PLYP (48.53 $\left.\mathrm{kcal} \cdot \mathrm{mol}^{-1}\right)$, M06-L (49.45 kcal $\left.\cdot \mathrm{mol}^{-1}\right), \mathrm{B} 97-3\left(48.46 \mathrm{kcal} \cdot \mathrm{mol}^{-1}\right)$ and CAM-S12h $\left(48.41 \mathrm{kcal} \cdot \mathrm{mol}^{-1}\right)$. Of these four, two give an excellent description of the RC well depth: M06-L $\left(-1.18 \mathrm{kcal} \cdot \mathrm{mol}^{-1}\right)$ and CAM-S12h $\left(-1.21 \mathrm{kcal} \cdot \mathrm{mol}^{-1}\right)$, while the other two underestimate it slightly (B97-3, -0.44 $\left.\mathrm{kcal} \cdot \mathrm{mol}^{-1}\right)$ or show a non-existent $\mathrm{RC}\left(\mathrm{B} 2 \mathrm{PLYP},+0.04 \mathrm{kcal}^{\mathrm{mol}}{ }^{-1}\right)$. The non-existence of a $\mathrm{RC}$ happens also for OPBE and OLYP with the augmented basis set (adz, atz, aqz), where the optimization proceeds towards reactants.

\subsection{Structural Parameters}

All methods used here confirm the early character of the $\mathrm{RC}$, with a distance between the nucleophile $(\mathrm{Nu})$ and the central carbon observed within the range of $2.97 \AA$ (B2PLYP) to $4.73 \AA$ (RHF) (see Table 2). These two values are, together with LDA (3.06 $\AA$ ), rather different from the other wavefunction and density functional methods that give values roughly between 3.4 and $4.0 \AA$. Moreover, this $\mathrm{C}-\mathrm{Nu}$ distance is the one that distinguishes the several methods for the deviations with respect to the CCSDT/atz results. The variation for the other structural parameters is much smaller (see Table 2). 
Table 2. Structural parameters $\left(\AA,{ }^{\circ}\right)$ for stationary points, obtained with atz basis set.

\begin{tabular}{|c|c|c|c|c|c|c|c|c|}
\hline & $\mathbf{r}(\mathbf{C}-\mathbf{H})^{a}$ & $\mathbf{r}(\mathbf{C}-\mathbf{L G})^{\mathbf{b}}$ & $\mathbf{r}(\mathrm{C}-\mathrm{Nu})^{\mathrm{c}}$ & $\mathbf{r}(\mathbf{C}-\mathbf{H})^{\mathbf{d}}$ & $\angle(\mathrm{H}-\mathrm{C}-\mathrm{LG})^{\mathrm{e}}$ & $\mathbf{r}(C-L G){ }^{f}$ & $\mathbf{r}(\mathbf{C}-\mathrm{H})^{\mathrm{g}}$ & $M A D^{h}$ \\
\hline RHF & 1.082 & 1.085 & 4.734 & 1.081 & 110.05 & 1.690 & 1.059 & 0.898 \\
\hline MP2 & 1.084 & 1.088 & 3.790 & 1.084 & 110.64 & 1.578 & 1.067 & 0.073 \\
\hline CCSD & 1.086 & 1.090 & 4.039 & 1.086 & 110.41 & 1.629 & 1.067 & 0.201 \\
\hline $\operatorname{CCSD}(\mathrm{T})$ & 1.088 & 1.092 & 3.857 & 1.087 & 110.55 & 1.629 & 1.069 & 0.020 \\
\hline CCSDT & 1.088 & 1.092 & 3.838 & 1.087 & 110.56 & 1.633 & 1.069 & 0 \\
\hline LDA & 1.097 & 1.104 & 3.055 & 1.098 & 111.60 & 1.570 & 1.081 & 0.786 \\
\hline PBE & 1.096 & 1.101 & 3.525 & 1.096 & 110.79 & 1.609 & 1.078 & 0.314 \\
\hline $\mathrm{PBE}-\mathrm{D}_{3}$ & 1.096 & 1.102 & 3.394 & 1.096 & 110.91 & 1.612 & 1.079 & 0.444 \\
\hline PBE0 & 1.089 & 1.093 & 3.586 & 1.089 & 110.74 & 1.603 & 1.071 & 0.253 \\
\hline $\mathrm{PBE} 0-\mathrm{D}_{3}$ & 1.089 & 1.093 & 3.473 & 1.089 & 110.83 & 1.606 & 1.072 & 0.366 \\
\hline PW91 & 1.094 & 1.099 & 3.523 & 1.094 & 110.76 & 1.614 & 1.076 & 0.315 \\
\hline BP86 & 1.096 & 1.100 & 3.862 & 1.096 & 110.54 & 1.620 & 1.079 & 0.033 \\
\hline revPBE & 1.097 & 1.101 & 4.085 & 1.097 & 110.36 & 1.624 & 1.079 & 0.248 \\
\hline OPBE & 1.094 & $\mathrm{n} / \mathrm{a}^{\mathrm{i}}$ & $\mathrm{n} / \mathrm{a}^{\mathrm{i}}$ & $\mathrm{n} / \mathrm{a}^{\mathrm{i}}$ & $\mathrm{n} / \mathrm{a}^{\mathrm{i}}$ & 1.571 & 1.078 & $n / a^{i}$ \\
\hline OLYP & 1.093 & $\mathrm{n} / \mathrm{a}^{\mathrm{i}}$ & $\mathrm{n} / \mathrm{a}^{\mathrm{i}}$ & $\mathrm{n} / \mathrm{a}^{\mathrm{i}}$ & $\mathrm{n} / \mathrm{a}^{\mathrm{i}}$ & 1.604 & 1.075 & $n / a^{i}$ \\
\hline B3LYP & 1.088 & 1.092 & 3.792 & 1.088 & 110.52 & 1.637 & 1.069 & 0.046 \\
\hline $\mathrm{B} 3 \mathrm{LYP}-\mathrm{D}_{3}$ & 1.089 & 1.093 & 3.565 & 1.088 & 110.67 & 1.642 & 1.069 & 0.272 \\
\hline BLYP & 1.094 & 1.099 & 4.100 & 1.094 & 110.32 & 1.652 & 1.075 & 0.263 \\
\hline B2PLYP & 1.093 & 1.100 & 2.967 & 1.093 & 111.50 & 1.559 & 1.079 & 0.874 \\
\hline M06 & 1.087 & 1.091 & 3.643 & 1.087 & 110.57 & 1.621 & 1.071 & 0.195 \\
\hline M06-2X & 1.087 & 1.091 & 3.309 & 1.087 & 110.93 & 1.612 & 1.069 & 0.529 \\
\hline M06-L & 1.085 & 1.088 & 4.088 & 1.085 & 110.33 & 1.646 & 1.069 & 0.251 \\
\hline B97 & 1.091 & 1.095 & 3.684 & 1.090 & 110.60 & 1.622 & 1.072 & 0.154 \\
\hline B97-3 & 1.087 & 1.091 & 3.789 & 1.087 & 110.50 & 1.612 & 1.069 & 0.053 \\
\hline B97- $\mathrm{D}_{2}$ & 1.095 & 1.100 & 3.892 & 1.095 & 110.46 & 1.672 & 1.077 & 0.069 \\
\hline TPSS & 1.092 & 1.097 & 3.709 & 1.092 & 110.49 & 1.660 & 1.075 & 0.238 \\
\hline TPSS $-\mathrm{D}_{3}$ & 1.092 & 1.098 & 3.490 & 1.092 & 110.64 & 1.645 & 1.073 & 0.348 \\
\hline TPSSh & 1.090 & 1.094 & 3.713 & 1.089 & 110.51 & 1.636 & 1.071 & 0.125 \\
\hline SSB-D & 1.087 & 1.093 & 3.459 & 1.087 & 110.79 & 1.567 & 1.072 & 0.384 \\
\hline $\mathrm{S} 12 \mathrm{~g}$ & 1.093 & 1.098 & 3.384 & 1.093 & 110.92 & 1.580 & 1.076 & 0.457 \\
\hline $\mathrm{S} 12 \mathrm{~h}$ & 1.087 & 1.092 & 3.400 & 1.087 & 110.89 & 1.600 & 1.070 & 0.439 \\
\hline $\mathrm{CAM}-\mathrm{S} 12 \mathrm{~h}$ & 1.087 & 1.091 & 3.417 & 1.086 & 110.87 & 1.606 & 1.069 & 0.421 \\
\hline $\begin{array}{c}\text { CAM-B3L } \\
\text { YP } \\
\end{array}$ & 1.087 & 1.090 & 3.724 & 1.086 & 110.61 & 1.635 & 1.067 & 0.114 \\
\hline
\end{tabular}

a $\mathrm{C}-\mathrm{H}$ distance in methane-reactant; ${ }^{\mathrm{b}} \mathrm{C}-\mathrm{LG}$ distance in $\mathrm{RC}, \mathrm{LG}=$ leaving group; ${ }^{\mathrm{c}} \mathrm{C}-\mathrm{Nu}$ distance in $\mathrm{RC}$, $\mathrm{Nu}=$ nucleophile; ${ }^{\mathrm{d}} \mathrm{C}-\mathrm{H}$ distance in $\mathrm{RC} ;{ }^{\mathrm{e}}$ angle $\mathrm{H}-\mathrm{C}-\mathrm{LG}$ in $\mathrm{RC} ;{ }^{\mathrm{f}} \mathrm{C}-\mathrm{LG}(\mathrm{C}-\mathrm{Nu})$ distance at $\mathrm{TS} ;{ }^{\mathrm{g}} \mathrm{C}-\mathrm{H}$ distance at $\mathrm{TS}$;

${ }^{\mathrm{h}}$ mean absolute deviation of distances compared to CCSDT/atz values; ${ }^{\mathrm{i}}$ not available due to dissociation towards reactants, i.e., no $\mathrm{RC}-$ complex found.

\subsection{Single-Point Calculations at CCSDT/atz Geometry}

The comparison of the energy profiles for the different methods is of course influenced to some extent by the different geometries used with the different methods. Therefore, and in order to make an honest comparison between the different methods we also performed single-point energy calculations 
using the CCSDT/atz geometries. Given in Table 3 are the results for all wavefunction and density functional methods.

Table 3. Energy profile (aqz basis, $\mathrm{kcal} \cdot \mathrm{mol}^{-1}$ ) using single-point calculations at CCSDT/atz geometry.

\begin{tabular}{cccccc}
\hline Method & RC & TS & Method & RC & TS \\
\hline RHF & 0.04 & 63.01 & B3LYP-D & -0.89 & 45.54 \\
MP2 & -0.86 & 50.52 & BLYP & -1.09 & 41.66 \\
CCSD & -0.60 & 53.03 & B2PLYP & -0.68 & 47.82 \\
CCSD(T) & -0.85 & 49.63 & M06 & -2.01 & 46.15 \\
CC-cf & -1.19 & 48.87 & M06-2X & -1.02 & 47.01 \\
& & & M06-L & -1.01 & 48.70 \\
LDA & -2.35 & 34.62 & B97 & -1.11 & 45.14 \\
PBE & -1.81 & 39.17 & B97-3 & -0.44 & 48.51 \\
PBE-D & -1.97 & 38.96 & B97-D & -1.16 & 41.18 \\
PBE0 & -1.07 & 45.18 & TPSS & -1.31 & 41.29 \\
PBE0-D 3 & -1.22 & 44.95 & TPSS-D & -1.49 & 40.99 \\
PW91 & -2.35 & 38.64 & TPSSh & -1.05 & 43.52 \\
BP86 & -0.58 & 40.35 & SSB-D & -1.99 & 41.65 \\
revPBE & -1.39 & 41.39 & S12g & -2.10 & 41.54 \\
OPBE & -1.04 & 43.73 & S12h & -1.32 & 46.79 \\
OLYP & -1.79 & 44.03 & CAM-S12h & -1.17 & 48.50 \\
B3LYP & -0.69 & 45.92 & CAM-B3LYP & -0.59 & 50.09 \\
\hline
\end{tabular}

By comparing the results from Table 3 with those from Table 1, it can be seen that the influence of the geometry is limited. The largest difference for the different methods observed is of the order of $0.4 \mathrm{kcal} \cdot \mathrm{mol}^{-1}$ (e.g., for LDA, $-2.74 \mathrm{kcal} \cdot \mathrm{mol}^{-1}$ for the RC at the LDA geometry, and $-2.35 \mathrm{kcal} \cdot \mathrm{mol}^{-1}$ at the CCSDT/atz geometry). However, the typical deviation is less than $0.1 \mathrm{kcal} \cdot \mathrm{mol}^{-1}$ (i.e., chemical accuracy); for instance, $\mathrm{PBE}-\mathrm{D}_{3}$ shows differences of 0.06 and $0.08 \mathrm{kcal} \cdot \mathrm{mol}^{-1}$ for the $\mathrm{RC}$ and TS energies with the two different geometries. All of this indicates that the energy surface is quite flat, as was already obvious from Figure 1.

\subsection{Competition with Proton Transfer Pathway}

An alternative reaction is possible in which the hydride abstracts a proton from methane. This leads to the formation of a methyl anion and $\mathrm{H}_{2}$ :

$$
\mathrm{H}^{-}+\mathrm{HCH}_{3} \Longrightarrow \begin{array}{ccc}
\delta- & \delta- \\
\mathrm{H}-\mathrm{H}^{-\cdots} \mathrm{CH}_{3}
\end{array} \Longrightarrow \mathrm{CH}_{3}{ }^{-}+\mathrm{HH}
$$

This alternative process is however associated with an endothermic reaction energy of $+21.35 \mathrm{kcal} \cdot \mathrm{mol}^{-1}$ at $\mathrm{S} 12 \mathrm{~h} / \mathrm{aqz}$. This pathway is beyond the scope of the present investigation which focuses on the thermoneutral identity $\mathrm{S}_{\mathrm{N}} 2$ reaction. 


\section{Experimental}

All wavefunction based calculations (Hartree-Fock, Second-order Møller-Plesset Perturbation Theory, Coupled Cluster Theory) have been performed with the Coupled-Cluster techniques for Computational Chemistry (CFOUR) [81,82] program version 1.2, using a variety of Dunning's correlation-consistent basis sets [83,84]: cc-pVXZ $(\mathrm{X}=\mathrm{D}, \mathrm{T}, \mathrm{Q}$, abbreviated as $d z$, tz and $q z$ respectively) and aug- $\mathrm{cc}-\mathrm{pVXZ}(\mathrm{X}=\mathrm{D}, \mathrm{T}, \mathrm{Q}$, abbreviated as adz, atz and aqz respectively). The continued-fraction approximant [46] for obtaining coupled-cluster energies toward the full configuration-interaction limit $(\mathrm{CC}-\mathrm{cf})$ has been used with equations $1 \mathrm{a}, \mathrm{b}$ to reach completeness of electron-correlation energies. The NWChem program [85] version 6.1 was used for all density functional calculations.

\section{Conclusions}

We have performed a benchmark study on the smallest bimolecular nucleophilic substitution $\left(\mathrm{S}_{\mathrm{N}} 2\right)$ reaction possible: $\mathrm{H}^{-}+\mathrm{CH}_{4} \rightarrow \mathrm{CH}_{4}+\mathrm{H}^{-}$, for which we obtained reference data at the near-full-CI coupled cluster limit using the continued-fraction approximant (CC-cf). Unlike typical $\mathrm{S}_{\mathrm{N}} 2$ reactions in the gas phase, which usually show a double-well potential, the current reaction shows an energy profile that resembles more the unimodal profile of the $\mathrm{S}_{\mathrm{N}} 2$ reaction in solution, with a relatively shallow reactant-complex well of only $-1.19 \mathrm{kcal} \cdot \mathrm{mol}^{-1}$ and a high barrier amounting to $48.87 \mathrm{kcal} \cdot \mathrm{mol}^{-1}$. All other computational methods also clearly show the steep reaction barrier that needs to be overcome $\left(34-50 \mathrm{kcal} \cdot \mathrm{mol}^{-1}\right.$ ), and the very shallow wells of the (ion-dipole) reactant complex. All density functionals have the tendency to underestimate the reaction barrier, while for the RC the deviations compared to CC-cf are much smaller $\left(<0.5 \mathrm{kcal} \cdot \mathrm{mol}^{-1}\right)$. Excellent results have been obtained with B97-3, M06-L and the newly developed CAM-S12h functional.

\section{Acknowledgments}

The following organizations are thanked for financial support: the Ministerio de Ciencia e Innovación (MICINN, project number CTQ2011-25086/BQU), the DIUE of the Generalitat de Catalunya (project number 2009SGR528, and Xarxa de Referència en Química Teòrica i Computacional), the National Research School Combination-Catalysis (NRSC-C), and the Netherlands Organization for Scientific Research (NWO-CW). Financial support from MICINN (Ministry of Science and Innovation, Spain) and the FEDER fund (European Fund for Regional Development) was provided by grant UNGI08-4E-003. Excellent service by the Centre de Serveis Científics i Acadèmics de Catalunya (CESCA) is gratefully acknowledged.

\section{Conflict of Interest}

The authors declare no conflict of interest. 


\section{References and Notes}

1. van Bochove, M.A.; Bickelhaupt, F.M. Nucleophilic substitution at C, Si and P: How solvation affects the shape of reaction profiles. Eur. J. Org. Chem. 2008, 2008, 649-654.

2. Bickelhaupt, F.M. Understanding reactivity with Kohn-Sham molecular orbital theory: E2-S 2 mechanistic spectrum and other concepts. J. Comput. Chem. 1999, 20, 114-128.

3. Olmstead, W.N.; Brauman, J.I. Gas-phase nucleophilic displacement reactions. J. Am. Chem. Soc. 1977, 99, 4219-4228.

4. Chabinyc, M.L.; Craig, S.L.; Regan, C.K.; Brauman, J.I. Gas-phase ionic reactions: Dynamics and mechanism of nucleophilic displacements. Science 1998, 279, 1882-1886.

5. Chandrasekhar, J.; Smith, S.F.; Jorgensen, W.L. Theoretical examination of the $\mathrm{S}_{\mathrm{N}} 2$ reaction involving chloride ion and methyl chloride in the gas phase and aqueous solution. J. Am. Chem. Soc. 1985, 107, 154-163.

6. Vayner, G.; Houk, K.N.; Jorgensen, W.L.; Brauman, J.I. Steric retardation of $\mathrm{S}_{\mathrm{N}} 2$ reactions in the gas phase and solution. J. Am. Chem. Soc. 2004, 126, 9054-9058.

7. Chandrasekhar, J.; Jorgensen, W.L. Energy profile for a nonconcerted $\mathrm{S}_{\mathrm{N}} 2$ reaction in solution. J. Am. Chem. Soc. 1985, 107, 2974-2975.

8. Chandrasekhar, J.; Smith, S.F.; Jorgensen, W.L. $\mathrm{S}_{\mathrm{N}} 2$ reaction profiles in the gas phase and aqueous solution. J. Am. Chem. Soc. 1984, 106, 3049-3050.

9. Jorgensen, W.L.; Buckner, J.K. Effect of hydration on the structure of an $\mathrm{S}_{\mathrm{N}} 2$ transition state. J. Phys. Chem. 1986, 90, 4651-4654.

10. Chen, X.; Regan, C.K.; Craig, S.L.; Krenske, E.H.; Houk, K.N.; Jorgensen, W.L.; Brauman, J.I. Steric and solvation effects in ionic $\mathrm{S}_{\mathrm{N}} 2$ reactions. J. Am. Chem. Soc. 2009, 131, 16162-16170.

11. Kim, Y.; Cramer, C.J.; Truhlar, D.G. Steric effects and solvent effects on $\mathrm{S}_{\mathrm{N}} 2$ reactions. J. Phys. Chem. A 2009, 113, 9109-9114.

12. Craig, S.L.; Brauman, J.I. Intramolecular microsolvation of $\mathrm{S}_{\mathrm{N}} 2$ transition states. J. Am. Chem. Soc. 1999, 121, 6690-6699.

13. Manikandan, P.; Zhang, J.; Hase, W.L. Chemical dynamics simulations of $\mathrm{X}^{-}+\mathrm{CH}_{3} \mathrm{Y} \rightarrow \mathrm{XCH}_{3}+$ $\mathrm{Y}^{-}$gas - phase $\mathrm{S}_{\mathrm{N}} 2$ nucleophilic substitution reactions. Nonstatistical dynamics and nontraditional reaction mechanisms. J. Phys. Chem. A 2012, 116, 3061-3080.

14. Kowalski, K.; Valiev, M. Extensive regularization of the coupled cluster methods based on the generating functional formalism: Application to gas-phase benchmarks and to the $\mathrm{S}_{\mathrm{N}} 2$ reaction of $\mathrm{CHCl}_{3}$ and $\mathrm{OH}^{-}$in water. J. Chem. Phys. 2009, 131, 234107.

15. Swart, M.; Solà, M.; Bickelhaupt, F.M. Energy landscapes of nucleophilic substitution reactions: A comparison of density functional theory and coupled cluster methods. J. Comput. Chem. 2007, $28,1551-1560$.

16. Galabov, B.; Nikolova, V.; Wilke, J.J.; Schaefer III, H.F.; Allen, W.D. Origin of the $\mathrm{S}_{\mathrm{N}} 2$ benzylic effect. J. Am. Chem. Soc. 2008, 130, 9887-9896.

17. Botschwina, $\mathrm{P}$. The saddle point of the nucleophilic substitution reaction $\mathrm{Cl}^{-}+\mathrm{CH}_{3} \mathrm{Cl}$ : Results of large-scale coupled cluster calculations. Theor. Chem. Acc. 1998, 99, 426-428. 
18. Botschwina, P.; Horn, M.; Seeger, S.; Oswald, R. Stationary points of the potential surface for the reaction $\mathrm{F}^{-}+\mathrm{CH}_{3} \mathrm{Cl} \rightarrow \mathrm{FCH}_{3}+\mathrm{Cl}^{-}$: Results of large-scale coupled cluster calculations. Ber. Bunsenges. Phys. Chem. 1997, 101, 387-390.

19. Gonzales, J.M.; Cox III, R.S.; Brown, S.T.; Allen, W.D.; Schaefer III, H.F. Assessment of density functional theory for model $\mathrm{S}_{\mathrm{N}} 2$ reactions: $\mathrm{CH}_{3} \mathrm{X}+\mathrm{F}^{-}(\mathrm{X}=\mathrm{F}, \mathrm{Cl}, \mathrm{CN}, \mathrm{OH}, \mathrm{SH}, \mathrm{NH}, \mathrm{PH})$. J. Phys. Chem. A 2001, 105, 11327-11346.

20. Gonzales, J.M.; Pak, C.; Cox, R.S.; Allen, W.D.; Schaefer III, H.F.; Császár, A.G.; Tarczay, G. Definitive ab initio studies of model $\mathrm{S}_{\mathrm{N}} 2$ reactions $\mathrm{CH}_{3} \mathrm{X}+\mathrm{F}^{-}\left(\mathrm{X}=\mathrm{F}, \mathrm{Cl}, \mathrm{CN}, \mathrm{OH}, \mathrm{SH}, \mathrm{NH}_{2}, \mathrm{PH}_{2}\right)$. Chem.-Eur. J. 2003, 9, 2173-2192.

21. Bento, A.P.; Solà, M.; Bickelhaupt, F.M. Ab initio and DFT benchmark study for nucleophilic substitution at carbon $\left(\mathrm{S}_{\mathrm{N}} 2 @ \mathrm{C}\right)$ and silicon $\left(\mathrm{S}_{\mathrm{N}} 2 @ \mathrm{Si}\right) . J$. Comput. Chem. 2005, 26, 1497-1504.

22. Bento, A.P.; Solà, M.; Bickelhaupt, F.M. E2 and $\mathrm{S}_{\mathrm{N}} 2$ reactions of $\mathrm{X}^{-}+\mathrm{CH}_{3} \mathrm{CH}_{2} \mathrm{X}(\mathrm{X}=\mathrm{F}, \mathrm{Cl})$; an ab initio and dft benchmark study. J. Chem. Theory Comp. 2008, 4, 929-940.

23. Bachrach, S.M.; Mulhearn, D.C. Nucleophilic substitution at sulfur: $\mathrm{S}_{\mathrm{N}} 2$ or addition-elimination? J. Phys. Chem. 1996, 100, 3535-3540.

24. Angel, L.A.; Ervin, K.M. Dynamics of the gas-phase reactions of fluoride ions with chloromethane. J. Phys. Chem. A 2001, 105, 4042-4051.

25. Angel, L.A.; Ervin, K.M. Gas-phase reactions of the iodide ion with chloromethane and bromomethane: Competition between nucleophilic displacement and halogen abstraction. J. Phys. Chem. A 2004, 108, 9827-9833.

26. Angel, L.A.; Garcia, S.P.; Ervin, K.M. Dynamics of the gas-phase reactions of chloride ion with fluoromethane: High excess translational activation energy for an endothermic $\mathrm{S}_{\mathrm{N}} 2$ reaction. J. Am. Chem. Soc. 2002, 124, 336-345.

27. Borisov, Y.A.; Arcia, E.E.; Mielke, S.L.; Garrett, B.C.; Dunning, T.H., Jr. A systematic study of the reactions of $\mathrm{OH}^{-}$with chlorinated methanes. 1. Benchmark studies of the gas-phase reactions. J. Phys. Chem. A 2001, 105, 7724-7736.

28. Glukhovtsev, M.N.; Pross, A.; Radom, L. Gas-phase identity $\mathrm{S}_{\mathrm{N}} 2$ reactions of halide anions with methyl halides: A high-level computational study. J. Am. Chem. Soc. 1995, 117, 2024-2032.

29. Glukhovtsev, M.N.; Pross, A.; Radom, L. Gas-phase identity $\mathrm{S}_{\mathrm{N}} 2$ reactions of halide ions at neutral nitrogen: A high-level computational study. J. Am. Chem. Soc. 1995, 117, 9012-9018.

30. Uggerud, E. Nature of the transition state in gas phase $\mathrm{S}_{\mathrm{N}} 2$ identity reactions: Correlation between nucleophilicity and proton affinity. J. Chem. Soc. Perkin Trans. 1999, 2, 1459-1463.

31. Wang, H.; Hase, W.L. Kinetics of $\mathrm{F}^{-}+\mathrm{CH}_{3} \mathrm{Cl} \mathrm{S} \mathrm{S}_{\mathrm{N}}$ nucleophilic substitution. J. Am. Chem. Soc. 1997, 119, 3093-3102.

32. Wladkowski, B.D.; Allen, W.D.; Brauman, J.I. The $\mathrm{S}_{\mathrm{N}} 2$ identity exchange reaction $\mathrm{F}^{-}+\mathrm{CH}_{3} \mathrm{~F} \rightarrow$ $\mathrm{FCH}_{3}+\mathrm{F}^{-}$: Definitive ab initio predictions. J. Phys. Chem. 1994, 98, 13532-13540.

33. Xiong, Y.; Zhu, H.-J.; Ren, Y. A theoretical study of the gas-phase ion pair $\mathrm{S}_{\mathrm{N}} 2$ reactions of lithium halide and methyl halide with inversion and retention mechanisms. J. Mol. Struct. (THEOCHEM) 2003, 664-665, 279-289.

34. Yu, Z.-X.; Wu, Y.-D. An $\mathrm{S}_{\mathrm{N}} 2-$ like transition state for alkene episulfidation by dinitrogen sulfide. J. Org. Chem. 2003, 68, 6049-6052. 
35. Sun, L.; Song, K.; Hase, W.L.; Sena, M.; Riveros, J.M. Stationary points for the $\mathrm{OH}^{-}+\mathrm{CH}_{3} \mathrm{~F} \rightarrow$ $\mathrm{CH}_{3} \mathrm{OH}+\mathrm{F}^{-}$potential energy surface. Int. J. Mass Spectrom. 2003, 227, 315-325.

36. Schmatz, S.; Botschwina, P.; Stoll, H. Coupled cluster calculations for the $\mathrm{S}_{\mathrm{N}} 2$ reaction $\mathrm{Cl}^{-}+$ $\mathrm{CH}_{3} \mathrm{Br} \rightarrow \mathrm{ClCH}_{3}+\mathrm{Br}^{-}$. Int. J. Mass Spectrom. 2000, 201, 277-282.

37. Schmatz, S.; Botschwina, P.; Hauschildt, J.; Schinke, R. Symmetry specificity in the unimolecular decay of the $\mathrm{Cl}^{-} \cdots \mathrm{CH}_{3} \mathrm{Cl}$ complex: Two-mode quantum calculations on a coupled-cluster [CCSD(T)] potential energy surface. J. Chem. Phys. 2001, 114, 5233-5245.

38. Parthiban, S.; de Oliveira, G.; Martin, J.M.L. Benchmark ab initio energy profiles for the gas-phase $\mathrm{S}_{\mathrm{N}} 2$ reactions $\mathrm{Y}^{-}+\mathrm{CH}_{3} \mathrm{X} \rightarrow \mathrm{CH}_{3} \mathrm{Y}+\mathrm{X}^{-}(\mathrm{X}, \mathrm{Y}=\mathrm{F}, \mathrm{Cl}, \mathrm{Br})$. Validation of hybrid dft methods. J. Phys. Chem. A 2001, 105, 895-904.

39. Matsubara, H.; Horvat, S.M.; Schiesser, C.H. Methyl radical also reacts by the frontside mechanism: An ab initio study of some homolytic substitution reactions of methyl radical at silicon, germanium and tin. Org. Biomol. Chem. 2003, 1, 1199-1203.

40. Lee, I.; Kim, C.K.; Sohn, C.K.; Li, H.G.; Lee, H.W. A high-level theoretical study on the gasphase identity methyl transfer reactions J. Phys. Chem. A 2002, 106, 1081-1087.

41. Zhao, Y.; González-García, N.; Truhlar, D.G. Benchmark database of barrier heights for heavy atom transfer, Nucleophilic substitution, Association, And unimolecular reactions and its use to test theoretical methods. J. Phys. Chem. A 2005, 109, 2012-2018.

42. Zhao, Y.; Truhlar, D.G. Density functional calculations of $\mathrm{E} 2$ and $\mathrm{S}_{\mathrm{N}} 2$ reactions: Implementation effects on calculated interaction energies. J. Chem. Theory Comp. 2010, 6, 1104-1108.

43. Swart, M.; Solà, M.; Bickelhaupt, F.M. A new all-round DFT functional based on spin states and $\mathrm{S}_{\mathrm{N}} 2$ barriers. J. Chem. Phys. 2009, 131, 094103.

44. Swart, M. A new family of hybrid functionals. Chem. Phys. Lett. 2013, doi:10.1016/j.cplett.2013.06.045.

45. Helgaker, T.; Ruden, T.A.; Jorgensen, P.; Olsen, J.; Klopper, W. A priori calculation of molecular properties to chemical accuracy. J. Phys. Org. Chem. 2004, 17, 913-933.

46. Goodson, D.Z. Extrapolating the coupled-cluster sequence toward the full configuration-interaction limit. J. Chem. Phys. 2002, 116, 6948-6956.

47. Dirac, P.A.M. Quantum mechanics of many-electron systems. Proc. R. Soc. London, Ser. A 1929, 123, 714-733.

48. Slater, J.C. A simplification of the Hartree-Fock method. Phys. Rev. 1951, 81, 385-390.

49. Vosko, S.H.; Wilk, L.; Nusair, M. Accurate spin-dependent electron liquid correlation energies for local spin-density calculations - A critical analysis. Can. J. Phys. 1980, 58, 1200-1211.

50. Perdew, J.P.; Burke, K.; Ernzerhof, M. Generalized gradient approximations made simple. Phys. Rev. Lett. 1996, 77, 3865-3868.

51. Grimme, S. Semiempirical GGA-type density functional constructed with a long-range dispersion correction. J. Comput. Chem. 2006, 27, 1787-1799.

52. Perdew, J.P.; Ernzerhof, M.; Burke, K. Rationale for mixing exact exchange with density functional approximations. J. Chem. Phys. 1996, 105, 9982-9985.

53. Adamo, C.; Barone, V. Toward reliable density functional methods without adjustable parameters: The PBE0 model. J. Chem. Phys. 1999, 110, 6158-6169. 
54. Ernzerhof, M.; Scuseria, G.E. Assessment of the Perdew-Burke-Ernzerhof exchange-correlation functional. J. Chem. Phys. 1999, 110, 5029-5036.

55. Perdew, J.P.; Chevary, J.A.; Vosko, S.H.; Jackson, K.A.; Pederson, M.R.; Singh, D.J.; Fiolhais, C. Atoms, molecules, solids, and surfaces-Applications of the generalized gradient approximation for exchange and correlation. Phys. Rev. B 1992, 46, 6671-6687.

56. Perdew, J.P.; Wang, Y. Accurate and simple analytic representation of the electron-gas correlation-energy. Phys. Rev. B 1992, 45, 13244-13249.

57. Becke, A.D. Density-functional exchange-energy approximation with correct asymptotic behavior. Phys. Rev. A 1988, 38, 3098-3100.

58. Perdew, J.P. Density-functional approximation for the correlation-energy of the inhomogeneous electron-gas. Phys. Rev. B 1986, 33, 8822-8824.

59. Zhang, Y.; Yang, W. Comment on "Generalized gradient approximation made simple". Phys. Rev. Lett. 1998, 80, 890.

60. Swart, M.; Ehlers, A.W.; Lammertsma, K. Performance of the OPBE exchange-correlation functional. Molec. Phys. 2004, 102, 2467-2474.

61. Handy, N.C.; Cohen, A.J. Left-right correlation energy. Molec. Phys. 2001, 99, 403-412.

62. Lee, C.; Yang, W.; Parr, R.G. Development of the Colle-Salvetti correlation-energy formula into a functional of the electron density. Phys. Rev. B 1988, 37, 785-789.

63. Becke, A.D. Density-functional Thermochemistry. III. The role of exact exchange. J. Chem. Phys. 1993, 98, 5648-5652.

64. Stephens, P.J.; Devlin, F.J.; Chabalowski, C.F.; Frisch, M.J. Ab initio calculation of vibrational absorption and circular dichroism spectra using density functional force fields. J. Phys. Chem. 1994, 45, 11623-11627.

65. Grimme, S. Semiempirical hybrid density functional with perturbative second-order correlation. J. Chem. Phys. 2006, 124, 034108.

66. Zhao, Y.; Truhlar, D.G. The M06 suite of density functionals for main group thermochemistry, thermochemical kinetics, noncovalent interactions, excited states, and transition elements: Two new functionals and systematic testing of four M06-class functionals and 12 other functionals. Theor. Chem. Acc. 2008, 120, 215-241.

67. Zhao, Y.; Truhlar, D.G. A new local density functional for main-group thermochemistry, transition metal bonding, thermochemical kinetics, and noncovalent interactions. J. Chem. Phys. 2006, 125, 194101.

68. Becke, A.D. Density-functional thermochemistry. 5. Systematic optimization of exchangecorrelation functionals. J. Chem. Phys. 1997, 107, 8554-8560.

69. Keal, T.W.; Tozer, D.J. Semiempirical hybrid functional with improved performance in an extensive chemical assessment. J. Chem. Phys. 2005, 123, 121103.

70. Tao, J.M.; Perdew, J.P.; Staroverov, V.N.; Scuseria, G.E. Climbing the density functional ladder: Nonempirical meta- generalized gradient approximation designed for molecules and solids. Phys. Rev. Lett. 2003, 91, 146401.

71. Staroverov, V.N.; Scuseria, G.E.; Tao, J.; Perdew, J.P. Comparative assessment of a new nonempirical density functional: Molecules and hydrogen-bonded complexes. J. Chem. Phys. 2003, 119, 12129-12137. 
72. Yanai, T.; Tew, D.P.; Handy, N.C. A new hybrid exchange-correlation functional using the Coulomb-attenuating method (CAM-B3LYP). Chem. Phys. Lett. 2004, 393, 51-57.

73. Swart, M.; Bickelhaupt, F.M.; Duran, M. Popularity poll density functionals 2012 (DFT2012). Available online: http://www.marcelswart.eu/dft-poll/news2012.pdf (accessed on 4 June 2013).

74. Pauling, L. The Nature of the Chemical Bond, 3rd ed.; Cornell University Press: Ithaca, NY, USA, 1960; pp. 505-563.

75. Frecer, V.; Miertus, S. Polarizable continuum model of solvation for biopolymers. Int. J. Quantum Chem. 1992, 42, 1449-1468.

76. Swart, M.; van Duijnen, P.T. DRF90: a polarizable force field. Molec. Simul. 2006, 32, 471-484.

77. Bickelhaupt, F.M.; Baerends, E.J.; Nibbering, N.M.M. The effect of microsolvation on E2 and $\mathrm{S}_{\mathrm{N}} 2$ Reactions: Theoretical study of the model system $\mathrm{F}^{-}+\mathrm{C}_{2} \mathrm{H}_{5} \mathrm{~F}+$ nHF. Chem. Eur. J. 1996, 2 , 196-207.

78. Wheeler, S.E.; Houk, K.N. Integration grid errors for meta-gga-predicted reaction energies: Origin of grid errors for the M06 suite of functionals. J. Chem. Theory Comp. 2010, 6, 395-404.

79. Swart, M.; Solà, M.; Bickelhaupt, F.M. Density functional calculations of E2 and $\mathrm{S}_{\mathrm{N}} 2$ reactions: Effects of the choice of method, Algorithm, And numerical accuracy. J. Chem. Theory Comp. 2010, 6, 3145-3152.

80. Pierrefixe, S.C.A.H.; Bickelhaupt, F.M. Hypervalence and the delocalizing versus localizing propensities of $\mathrm{H}_{3}{ }^{-}, \mathrm{Li}_{3}{ }^{-}, \mathrm{CH}_{5}{ }^{-}$and $\mathrm{SiH}_{5}$. Struct. Chem. 2007, 18, 813-819.

81. Harding, M.E.; Metzroth, T.; Gauss, J. Parallel calculation of CCSD and CCSD(T) analytic first and second derivatives. J. Chem. Theory Comp. 2008, 4, 64-74.

82. Stanton, J.F.; Gauss, J.; Harding, M.E.; Szalay, P.G.; with contributions from A.A. Auer, R.J.B., U. Benedikt, C. Berger, D.E. Bernholdt, Y.J. Bomble, L. Cheng, O. Christiansen, M. Heckert, O. Heun, C. Huber, T.-C. Jagau, D. Jonsson, J. Jusélius, K. Klein, W.J. Lauderdale, D.A. Matthews, T. Metzroth, D.P. O’Neill, D.R. Price, E. Prochnow, K. Ruud, F. Schiffmann, W. Schwalbach, S. Stopkowicz, A. Tajti, J. Vázquez, F. Wang, J.D. Watts; including the integral packages MOLECULE (J. Almlöf and P.R. Taylor), PROPS (P.R. Taylor), ABACUS (T. Helgaker, H.J. Aa. Jensen, P. Jørgensen, and J. Olsen), and ECP routines by A.V. Mitin and C. van Wüllen CFOUR 1.2, see http://www.cfour.de, CFOUR 1.2; Austin, TX, USA; Mainz, Germany, 2010.

83. Dunning, T.H., Jr. Gaussian basis sets for use in correlated molecular calculations. I. The atoms boron through neon and hydrogen. J. Chem. Phys. 1989, 90, 1007-1023.

84. Dunning, T.H., Jr.; Peterson, K.A.; Wilson, A.K. Gaussian basis sets for use in correlated molecular calculations. X. The atoms aluminum through argon revisited. J. Chem. Phys. 2001, 114, 9244-9253.

85. Valiev, M.; Bylaska, E.J.; Govind, N.; Kowalski, K.; Straatsma, T.P.; Van Dam, H.J.J.; Wang, D.; Nieplocha, J.; Apra, E.; Windus, T.L.; et al. NWChem: A comprehensive and scalable opensource solution for large scale molecular simulations. Comp. Phys. Comm. 2010, 181, 1477-1489.

Sample Availability: Cartesian coordinates of all stationary points are available from the authors.

(C) 2013 by the authors; licensee MDPI, Basel, Switzerland. This article is an open access article distributed under the terms and conditions of the Creative Commons Attribution license (http://creativecommons.org/licenses/by/3.0/). 